\title{
Factors influencing non-green consumers' purchase intention: A partial least squares structural equation modelling (PLS-SEM) approach
}

\author{
Siti Munerah ${ }^{a,}{ }^{*}$, Kian Yeik Koay ${ }^{a}$, Seethaletchumy Thambiah ${ }^{b}$ \\ ${ }^{a}$ Department of Marketing, Sunway University Business School, Sunway University, Malaysia \\ ${ }^{\mathrm{b}}$ Faculty of Management, Multimedia University, Malaysia
}

\section{A R T I C L E I N F O}

\section{Article history:}

Received 8 May 2019

Received in revised form

23 May 2020

Accepted 9 September 2020

Available online 13 September 2020

Handling editor: Prof. Jiri Jaromir Klemeš

\section{Keywords:}

Norm activation theory

ECSR initiatives

Green beauty products

\begin{abstract}
A B S T R A C T
The shift of consumers buying preference toward green beauty products can alleviate environmental degradation to a certain extent. This study investigated the factors that could affect non-green consumers purchase intention of green beauty products. Through the lens of non-green consumers of green beauty products, the norm activation theory was employed as the underpinning theory in this paper. A quantitative method, based on the partial least squares structural equation modelling, was used to verify the proposed hypotheses. The findings displayed that norm activation theory activators, such as ascription of responsibility, efficacy, social norm and environmental corporate social responsibility (ECSR) initiatives showed a significant impact on personal norm, while awareness of consequences had no influence on personal norm as an activator. Corresponding results disclosed that awareness of consequences, efficacy, social norm, ECSR initiatives, and personal norm exhibited a significant impact on the purchase intention of green beauty products. The study further assessed the effectiveness of personal norm as a mediator variable and found that personal norm mediated four out of five activators of nongreen consumers' purchase intention of green beauty products. According to the research, a further inclusive analysis can be conducted in the future to evaluate the purchase intention of green beauty products among non-green consumers and existing consumers on the foundation of norm activation theory.
\end{abstract}

(C) 2020 Elsevier Ltd. All rights reserved.

\section{Introduction}

The everyday use of beauty products poses a threat to the environment. Tiny plastic beads or microbeads in facial scrubs, for instance, are not biodegradable and their waste is often released into the ocean, polluting the environment (Lopez, 2014; UNEP, 2015). Common ingredients of cosmetic products found in sunscreen, shampoos, moisturisers, liquid soaps, and hair conditioners, such as parabens, triclosan, and siloxane are discharged into aquatic and terrestrial environments daily. These have posed ecological risk and toxic effects on plants and animal species (Juliano and Magrini, 2017; Jardak et al., 2016). Parabens can be detected in the air when it is released during the production of

\footnotetext{
* Corresponding author. Department of Marketing, Sunway University Business School 5, Jalan University, Bandar Sunway, 47500, Petaling Jaya, Selangor, Malaysia. E-mail address: munerahs.s@gmail.com (S. Munerah).
}

beauty products (Juliano and Magrini, 2017). Siloxane is classified as a chemical compound known in the category of volatile organic compounds, which can evaporate in the air and affect air quality (NOAA Research News, 2018). A study led by NOAA, a research centre of National Oceanic and Atmospheric Administration, found that among others, Siloxane's presence in personal care products causes air pollution when released into the air, comparable to vehicular emission (NOAA Research New, 2018). One way to prevent environmental pollution from the use of beauty products is to switch to green beauty products. In the present study, a green beauty product is described as a personal care product that has been manufactured to offer the least harmful environmental effect at every level of lifespan, can be recycled or reused, has biodegradable properties, or is packaged in an eco-friendly manner, and allows for the long-lasting conservation of the biological ecosystem (OECD, 2009). Green beauty products from this definition also comprises cosmetic products that have been validated as green or have been eco-labelled. (see Fig. 1) 


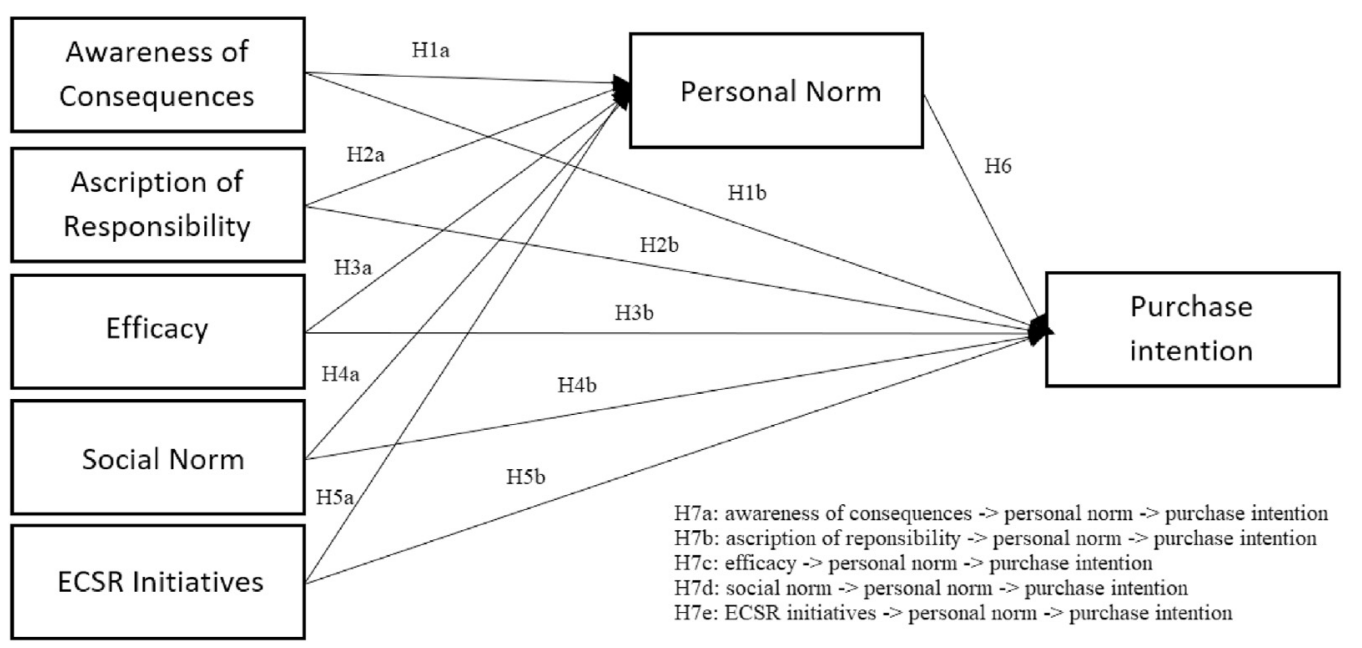

Fig. 1. Research model.

As mentioned previously, to reduce the negative impact of beauty products on the ecosystem is to shift to the consumption of green beauty products. Hence, cosmetic users play a significant role in contributing to or reducing pollution through their choice and use of products. Green buying choice, or the conscious decision of buying environmentally-friendly products, can offer a solution to environmental problems caused by unsustainable cosmetic consumption (Chekima et al., 2015). However, some users do not prefer to buy green beauty products even though the goods appeal to them (Sharma and Garisson, 2014). Devinney et al. (2010) argued that in terms of purchasing proper or green products, users become unwilling to sustain nature once they realise that they must spend more money. To address this issue, Devinney et al. (2010) recommended an emphasis on "social" consumerism or consumer social responsibility $\left(C_{N} S R\right)$ to understand users' behavioural consumption. $\mathrm{C}_{\mathrm{N}} \mathrm{SR}$ represents three components. The first component relates to the users' expressed attentiveness to specific motivations such as charity and participation in protests, and the second component may not even relate to any specific attitude since it is associated to stated opinions in surveys or other methods of market research. The third component of $C_{N} S R$ is focused in the present study, which signifies the conveyed concerns pertaining to buying or non-buying behaviour.

This research looks at a different angle of consumerism, i.e. users' non-buying behaviour. These users are known as non-green consumers of green beauty products, whose behaviour is yet to be examined in detail within the context of the green cosmetics industry. The non-green consumers of green beauty products in this context refer to those do not purchase or are not the existing consumer of green beauty products. Research on this industry has mainly dealt with marketing policies (Kim and Chung, 2011), and numerous researchers in consumer behaviour studies in the field of cosmetics have mainly explored the existing users' perspective of green beauty products (e.g. Lalit and Sahasakmontri, 1998; Kim and Chung, 2011; Pudaruth et al., 2015). Joshi and Rahman (2015) mentioned that various elements may have hindered green buying behaviour, including the fact that consumers' choice of products is not drawn from their rationale or emotional impulses, but based on their behaviour of consumption in the past. Therefore, a study to focus on non-green consumers' buying behaviour is paramount, not only to better understand their purpose of buying green beauty products and changing their past behaviour in the process, but also to identify the possible determinants that may have influenced them to adopt a more environmentally responsible usage.
This study aims to propose and test a model based on the Norm Activation Theory (NAT) to understand non-green consumers' purpose of buying green beauty products from the perspective of consumer social responsibility $\left(\mathrm{C}_{\mathrm{N}} \mathrm{SR}\right)$. Devinney et al. (2006) described $\mathrm{C}_{\mathrm{N}} \mathrm{SR}$ as the consumers' purposive and cognisant inclination of deciding on a specific selection for usage, on the basis of individual and ethical principles. Personal and moral beliefs are intrinsic in nature; thus, the NAT is chosen as the underpinning theory, proposing that pro-social conduct is motivated by one's personal norm (PN), which denotes a person's ethical commitment to accomplish or abstain a distinctive act. Emphasis is put on an individual's ethical contemplations (Zhang et al., 2013).

It is noted that the ultimate challenge of CSR (corporate social responsibility) is whether $\mathrm{C}_{\mathrm{N}} \mathrm{SR}$ can be nurtured independently, and whether there will be no valuable creation by CSR without feedback from $C_{N} S R$ (Devinney et al., 2006). The current study focuses on environmental context; thus, it proposes the inclusion of environmental corporate social responsibility (ECSR) initiatives, a subcomponent of CSR, as additional activators of personal norm (PN). ECSR signifies an organisation's endeavours in blending its commercial procedures with initiatives for the environment, and handling investors without sacrificing the fiscal progress of its trade (Nor Irwani et al., 2014). Companies' ECSR initiatives may indirectly shape social norm, serving as a reference to society of how an individual should behave. Behavioural change among consumers is possible with corporate social responsibility (CSR) initiatives (Khojastehpour and Johns, 2014). According to Bhattacharya and Sen (2004), corporate participation or support in issues relating to the society as a whole, can inspire people to undergo some form of "behaviour modification." The transformation can be due to changes in personal norm (PN), the result of which can affect consumers' buying decision towards more socially and environmentally responsible products (Grimmer and Bingham, 2013).

Therefore, this study aims to understand non-green consumers' purchase intention of green beauty products using the NAT. A total of 478 non-green consumers data were collected and analysed using a partial least squares structural equation modelling analysis. To achieve this research objective, the specific research question to be answered is:

RQ: what are the factors (using the NAT) influencing non-customers' purchase intention of green beauty products? 


\section{Literature review and hypotheses}

\subsection{Consumer social responsibility $\left(C_{N} S R\right)$}

The overall cosmetics industry is worth USD $\$ 532$ billion globally in 2019, while the natural cosmetics market is valued at USD\$36.2 billion in the same year (Shahbandeh, 2019). From the equation, the natural cosmetics market only makes up $6.8 \%$ of the overall cosmetics market share. As highlighted by Sharma and Garisson (2014), although green beauty products are interesting to consumers, they do not convert into actual purchases. Little explanation was provided in the literature concerning the gap in consumers' behaviour between their ethical consumptions and their unethical choices (Belk et al., 2005). According to Belk et al. (2005), it is particularly obvious when it comes to buying behaviour on the issues that they claimed to be concerned about. The ethical or green consumption desire has not become reality when it comes to actual spending (Devinney et al., 2010). The gap between consumers' desire and their actual spending have caused the rise on the discussion pertaining to $\mathrm{C}_{\mathrm{N}} \mathrm{SR}$ from various researchers, such as Devinney et al. (2010), Manning (2013), Caruana and Chatzidakis (2014), Quazi et al. (2016), and Schlaile et al. (2018).

Consumer social responsibility $\left(\mathrm{C}_{\mathrm{N}} \mathrm{SR}\right)$ has several definitions. Schlaile et al.'s (2018) compilations of $C_{N}$ SR definitions have shown the term to be closely related to consumers' consumption choice in shifting towards socially and environmentally friendly products. Among others, Webster (1975) defined $\mathrm{C}_{\mathrm{N}} \mathrm{SR}$ as the conscious decision of consumers to consider the repercussions of the products being consume on the general public. These consumers utilised their buying power to influence positive social change. Webster's (1975) definition focuses on the "social aspect," while Antil's (1984) definition of $C_{N} S R$ deals with the "environmental aspect". Based on Antil's (1984) definition of $C_{N}$ SR, consumers decide to buy a product based on considerations toward the environmental impact of the products being consumed and are concerned with the negative consequences of the products on the environment. However, Devinney et al.'s (2006) definition of $C_{N} S R$ touches on the aspect of consumers' personal and moral beliefs, stating that it is a consumer's deliberate and mindful verdict to buy a product on the basis of individualistic and ethical principles. $\mathrm{C}_{\mathrm{N}} \mathrm{SR}$ can be understood as the buying or non-buying inclination and the expressed views given in surveys or other types of market study. Even though the definition of $\mathrm{C}_{\mathrm{N}} \mathrm{SR}$ includes consumers' consumption component, Schlaile et al. (2018) further defined $C_{N} S R$ specifically on consumer social responsibility consumption (SRC). SRC is defined as "a social action that involves the act of consuming and simultaneously entails (i) taking into account, (ii) gathering information about, and ultimately (iii) avoiding the (foreseeable) negative consequences the current action engenders with regard to past, present, and the future behaviour of others" (p. 569).

Consumer social responsibility $\left(\mathrm{C}_{\mathrm{N}} \mathrm{SR}\right)$ has a solid association with corporate social responsibility (CSR). Corporate social responsibility (CSR) is a voluntary effort by corporations to improve the quality of the society and the environment. The three elements of CSR are the social responsibility, economic responsibility, and the environmental responsibility (Van Marrewijk, 2003). All three CSR components emphasise on corporate ethics. According to Belk et al. (2006), a business' ethical behaviour may influence the ethical behaviour of consumers. There is a link between business and consumers in relation to ethical behaviour. Researchers in the past have reiterated that CSR initiatives by corporations may succeed if it is propelled by consumer social responsibility $\left(C_{N} S R\right)$ (Manning, 2013; Caruana and Chatzidakis, 2014; Vitell, 2015; Schlaile et al., 2018). In relation to that, the environmental portion of CSR is often overlooked or discussed in the past by researchers (Nik Ramli et al., 2014). Thus, this paper focuses on environmental corporate social responsibility (ECSR) initiatives to close the gap in this area of study by concentrating on consumers' non-buying behaviour-a different angle of $C_{N} S R$. The non-buyer is also known as the nongreen consumer of green beauty products in the context of this paper.

\subsection{Green purchase intention (PI)}

Green PI is the likelihood and willingness to consume the product that has biodegradable features (Nik Ramli, 2009; Yusof et al., 2013). Another definition is the probability of consumers to purchase green products is based on their environmental needs (Chen and Chang, 2012; Kong et al., 2014). Consumers are aware that such behaviour will contribute to environmental cause (Chen and Lee, 2015). Green PI will lead to actual green behaviour.

Green behaviour is demonstrated in the buying behaviour. Green consumers purchase green products as a preventive measure of further deterioration of the environment (Ergen et al., 2014; Tan and Lau, 2010; Young et al., 2010). According to Gilg et al. (2005) green behaviour are based on purchase decision (green consumption), habits (energy and water conservation) and recycling. There are two categories of green behaviour of interest, which are recycling and environmentally friendly product purchasing (Park and Ha, 2012). Green behaviour can be divided into different distinct categories and green consumerism has been listed as one in these categories (Stern, 2000; Rasool, 2013). The decision of green purchasing helps reduced the effects of higher-impact products since they are substituted with products that are environmentally friendly (Moser, 2015).

\subsection{Norm activation theory (NAT)}

Schwartz described the NAT as the relationship between personal norm (PN), activators, and behaviour (Schwartz, 1970, 1977; Schwartz and Howard, 1984; Harland et al., 2007), and further purported that PN needs activators that will influence pro-social behaviour (Schwartz, 1977). To strengthen the predictive power of the NAT model, social norm (SN) is added as one of the model's variables (Bamberg et al., 2007; Onwezen et al., 2014; Han, 2014), along with awareness of consequences (AC), ascription of responsibility (AR), and efficacy. Several studies have demonstrated how the NAT can be useful in predicting environmentally friendly behaviour (Ebreo et al., 2003; Harland et al., 2007; Matthies et al., 2012; Zhang et al. 2013; Van der Werff and Steg, 2015). Green PI, which denotes the prospect and inclination of buying products with environmentally friendly features (Nik Ramli, 2009; Yusof et al., 2013), can be explained using the NAT and PN, the latter being the greatest contributor to green PI (Hofenk et al., 2010).

\subsubsection{Awareness of consequences (AC)}

$A C$ is the NAT's first activator, referring to the degree that a person is mindful of harmful consequences of not acting prosocially (De Groot and Steg, 2009). It is one of the key variables in predicting environmentally friendly purpose based on Schwartz's (1977) NAT, as the AC of global and local environmental problems can result in environmentally-friendly-related behaviour (Schultz et al., 2005; Milfont et al., 2010). Likewise, the degree of a person's participation with pro-environmental conduct depends on the magnitude of one's alertness to the implications and outcomes of ecological complications (Steg and De Groot, 2010). A study on residents of a tourist site in China showed that the AC of disasters affects the residents' behaviour towards environmental protection (Zhang et al., 2014). In another related study on carbon footprint mitigation, it was found that the increase in AC positively increased 
reported environmental behaviour (Vaske et al., 2015). Thus, it follows that consumers will consciously select more environmentally friendly products when the awareness to ecological complications is substantial (Ergen et al., 2014). A research on energy saving conducted by Van der Werff and Steg (2015), further showed that AC positively predicted PN. Accordingly, PN increases when AC increases, which will eventually affect environmental behaviour (Vaske et al., 2015).

H1a. AC has a direct association with PN.

H1b. AC has a direct association with PI of green beauty products.

\subsubsection{Ascription of responsibility (AR)}

The second activator of the underpinning theory is AR. According to Steg and De Groot (2010), AR refers to "the feeling of responsibility to the problems" (p. 727). A study by Ebreo et al. (2003) showed that AR significantly predicted environmentalrelated behaviour, whereby a person will tend engage in waste reduction behaviour when the responsibility is ascribed to oneself. Furthermore, a study conducted by Vaske et al. (2015) on carbon footprint mitigation, showed that an increase in AR increases reported environmental behaviour, positively affecting PN. De Groot and Steg (2009) too, surmised that AR positively affects PN following their various studies on pro-social intention, while Zhang et al. (2014) found that the effects of AR on PN will lead to environmentalism. Previous studies have showed positive impacts of AR on PN and intention, specifically in the area of green behaviour. The PI of consumers to purchase green products are considered as green behaviour (Park and Ha, 2012). Thus, the effectiveness of AR on PN and intention are measured in this study.

H2a. AR has a direct association with PN.

H2b. AR has a direct association with PI of green beauty products.

\subsubsection{Efficacy}

The third activator, efficacy is the ability to identify actions that can help reduce a problem (Schwartz, 1977; Harland et al., 2007; Steg and De Groot, 2010). Efficacy is measured through self-efficacy and outcome-efficacy in this study. Self-efficacy is a person's confidence to perform a specific behaviour (Steinhorst et al., 2015). An individual should have the belief of one's ability to perform the action that has been identified, as to minimise the problem at hand. Self-efficacy is one of the factors that increases a person's purpose to buy green beauty products (Ling, 2013). A study conducted on tourists and environmental protection showed that self-efficacy significantly affects the willingness of individuals to pay for environmental protection when travelling (Doran et al., 2015). For buying green beauty products, self-efficacy is proven to have the strongest impact on behaviour (Ling, 2013). Self-efficacy extends one's purpose to behave pro-environmentally (Payne, 2013) and the lack of self-efficacy is one of the barriers to pro-environmental behaviour (Gifford, 2011). The belief in one's own capacity to make a difference will lead to the feeling of ethical responsibility or PN (Schwartz, 1977; Turaga et al., 2010). Outcome-efficacy is a person's empathy towards altering one's behaviour to help minimise or solve a problem (Van der Werff and Steg, 2015). Previous studies have found that outcome-efficacy is one of the factors that activates PN (van de Werff and Steg, 2015); Steg and De Groot (2010).

H3a. : Efficacy has a direct association with PN.

H3b. : Efficacy has a direct association with PI of green beauty products.

\subsubsection{Social norm (SN)}

$\mathrm{SN}$ is added as the fourth activator of PN and is integrated into the NAT. SN refers to an individual's awareness of the social pressures of performing, or not performing, an action (Han, 2014). Green society, green movements, and environmentalists are among the SN factors that influence consumers to go green (Rezai et al., 2013). SN has been found to have a direct impact on PN (Thøgersen, 2006; Bamberg et al., 2007; Onwezen et al., 2013) or the responsibility to accomplish an action due to an internalised feeling. Therefore, from a theoretical perspective, SN has a strong role in the application of the NAT due to its positive outcome on PN (Matthies et al., 2012; Lauper et al., 2015). Nevertheless, previous studies conducted by Matthies et al. (2012) and done by Lauper et al. (2015) investigated the field of personal recycling behaviour and car drivers' purpose in averting street-traffic noise. This present study examines the efficiency of SN on PN among the non-green consumers' purpose to buy green beauty products. In addition, the efficiency of SN on non-green consumers' behavioural purpose to buy green beauty products will be inspected in this study. Previous research conducted by Han (2014) found that SN also has a direct impact on behavioural purpose, particularly proenvironmental behaviour (Garcia-Valinas et al., 2012), and it has been proven that $\mathrm{SN}$ is a vital constituent in predicting individuals' pro-environmental purchase intentions (Han et al., 2015). Similarly, in terms of green beauty products, the Theory of Planned Behaviour was applied and showed that $\mathrm{SN}$ has a significant direct correlation with the PI of green beauty products (Hsu et al., 2017). The effectiveness of SN on PI in this paper is from the perspectives of the non-green consumers of green beauty products, as well as applying the NAT as the underpinning theory.

H4a. : SN has direct association with PN.

H4b. : SN has direct association with PI of green beauty products.

\subsubsection{Personal norm (PN)}

PN has been proven to affect pro-environmental behaviour (Kaiser et al., 2005; Biel and Thøgersen, 2007; Zhang et al., 2014) and purpose (Steg and de Groot, 2010). It is defined as a "moral obligation to perform or refrain from specific actions" (Schwartz and Howard, 1981, p. 191). Regarding pro-environmental behaviour, PN was discovered to be the substantial predictor of energysaving actions, on the whole (Van der Werff and Steg, 2015). Meanwhile, Park and Ha (2012) specified that the purpose to recycle relies on a person's $\mathrm{PN}$ in recycling behaviours, and correspondingly, Hofenk et al. (2010) revealed that PN has a major bearing on pro-environmental PI. PN balances the purpose to accomplish a behaviour and is able to predict people's private emotions about pro-environmental behaviour (Onwezen et al., 2014).

H6. PN has direct association with PI of green beauty products.

\subsubsection{ECSR initiatives}

ECSR initiatives indicate an organisation's endeavours to blend environmental initiatives with its commercial procedures, and to manage investors without sacrificing the fiscal progress of the company's trade (Nor Irwani et al., 2014). Eco-labels, cause-related movements and environmental movements are some elements of ECSR initiatives, which have been recognised to impact company reputation significantly (Nor Irwani et al., 2014) and boost users' faithfulness (Nik Ramli et al., 2014). According to Kaur (2014), consumers who are exposed to corporate green initiatives will shift towards greener consumption. The shift signifies that consumers react positively to corporate CSR activities (Wigley, 2008) and that ECSR initiatives can directly and indirectly affect PI (Khojastehpour 
and Johns, 2014). The findings by Murphy et al. (2010), and Grimmer and Bingham (2013) that consumers prefer buying green products from companies perceived to be environmentally responsible is supported by Feldman and Vasquez-Parraga (2013), who deduced that companies' environmental commitment is considered during the decision-making process of buying socially responsible products.

Eco-labels and cause-related campaigns have also been found to have a significant impact on consumers' attitude and purpose to buy green products (Annuar and Mohamad, 2012; Kong et al., 2014), while other ECSR initiatives, such as environmental advertising, focus on education that can create awareness on the environment and nature among consumers (Zhu, 2013). Environmental advertising that highlights behavioural consequences of unsustainable behaviour affects consumers positively towards sustainable behaviour (White et al., 2011). Consumers become enthusiastic to promote cause-related movements because of socio-emotional and economic motives (Folse et al., 2010). ECSR initiative elements, such as environmental advertising can exploit the plea to conscience, which provokes emotions of accountability among consumers (Jimenez and Yang, 2008). Conscience can then affect people's ethical responsibility (Kaiser and Shimoda, 1999), which relates to their PN (Schwartz and Howard, 1981).

PN is the central component of the NAT. To investigate the effectiveness of ECSR initiatives in enhancing the PI among the nongreen consumers of green beauty products, ECSR initiative is integrated into the model of the NAT.

H5a. : ECSR initiatives has direct association with PN.

H5b. : ECSR initiatives has direct association with PI of green beauty products.

\subsection{Personal norm as a mediator}

This study also proposes PN as a mediator of the relationships between green behaviour, and both AC and AR (Vaske et al., 2015). According to Schwartz (1977), once PN is activated by AC, it can become the mediator to behavioural purpose. The purpose to carry out an ecological related behaviour further enhances AC through PN (Zhang et al., 2018). Besides AC, PN has also been found to be the mediator for AR with behavioural intention such as the PI of energy saving appliances (Zhang et al., 2019).

In a recent study by Joanes (2019) it was found that through PN, the intention to reduce clothing usage was strengthened due to outcome efficacy. PN has also been found to mediate self-efficacy and buying behaviour. When consumers have higher belief about their environmentalism, it their green buying behaviour via PN is affected (Song et al., 2019). Another activator of PN added in this paper, is SN. Wan et al. (2014) found that consumers who have high levels of SN are more likely to develop high levels of PN, which subsequently leads to high levels of green buying. PN has been proven to have a strong role as a mediator for the NAT activators with green-related behaviour.

ECSR initiatives are integrated into the model of the NAT. Previously, PN has played a mediating role in other areas of environmentalism, such as pro-environmental spillover (Steinhorst et al., 2015), and environmental concern (Song et al., 2019) with behavioural purpose. In this research, the effectiveness of PN as a mediator for ECSR initiatives and PI of green beauty products is investigated. Based on the discussions above, the following hypotheses are developed:

H7a. : PN mediates the relationship between AC and the PI of green beauty products
H7b. : PN mediates the relationship between AR and the PI of green beauty products

H7c. : PN mediates the relationship between efficacy and the PI of green beauty products

H7d. : PN mediates the relationship between SN and the PI of green beauty products

H7e. : PN mediates the relationship between ECSR initiatives and the PI of green beauty products

The full research model is shown in Table 1:

\section{Methodology}

\subsection{Sample and procedure}

The current study employed a quantitative research design by means of a survey questionnaire method. A pre-test was conducted to identify potential problems which might have been overlooked by the researchers. Several academic experts were invited to examine the face validity of each construct's scale. Next, smallscaled study was conducted, known as a pilot study, by distributing questionnaires to 32 non-green consumers of environmentally friendly beauty products to examine the reliability of each scale. Also, some of the respondents were interviewed to provide feedback on the questionnaire. Changes were made to the layout, the wordings, and the instruction, to enhance the quality of the questionnaire. The preliminary reliability results generated from the pilot test showed that the Cronbach's alpha values for all constructs exceeded the acceptable value of 0.6.

The sampling frame of this study is cosmetic consumers who have no prior experience of using green beauty products. Hence, a filter question was included in the questionnaire to ask whether they have any experience using green beauty products in the past. Those who answered 'yes' were dismissed from the sampling frame, i.e. excluded from the final data. Questionnaire survey forms were distributed to respondents, mainly at venues such as shopping malls, cosmetics chain stores, and hypermarkets with cosmetics aisles, from nine different states of Malaysia comprising Johor, Negeri Sembilan, Melaka, Kuala Lumpur, Selangor, Penang, Pahang, Kelantan, and Kedah. 478 useable data were received from the 850 distributed questionnaire survey forms. Based on the calculation of $G^{*}$ Power analysis, the study had a sufficient sample size as it exceeded the minimum sample requiring 98 .

The gender statistics showed that males are $42.7 \%$ and females are 57.3\%. 164 respondents (34.3\%) were high school graduates, 144 (30.1\%) respondents were degree holders, and the remaining were students at primary $(0.6 \%)$, secondary (5.4\%), diploma (24.1\%), Master's $(4.40 \%)$ and $\mathrm{PhD}(1 \%)$ levels. The majority of the respondents (52.1\%) had an average monthly income of less than RM 2,000, and most respondents (51.7\%) were from the age group of $21-30$ years.

\subsection{Measures}

Awareness of Consequence: Adapted from Han (2014), the scale to measure AC consists of 5 items. The response format is in a 5-point Likert's Scale ranging from strongly disagree (1) to strongly agree (5).

Ascription of Responsibility: The study measured AR using a 5item scale adapted from past studies (Ebreo et al., 2013; Han, 2014). Respondents completed the measure using a 5-point Likert's Scale (1-strongly disagree, 5-strongly agree).

Efficacy: A five-item scale was used to measure efficacy adapted from past studies (Steg and De Groot, 2010; Van der Werff and Steg, 2015; Steinhorst et al. 2016). The response options ranged from 1 
Table 1

Measurement model.

\begin{tabular}{|c|c|c|c|c|c|}
\hline Constructs & Items & Outer Loadings & Cronbach's Alpha & Composite Reliability & AVE \\
\hline \multirow[t]{5}{*}{ Ascription of Responsibility } & AR2 & 0.815 & 0.854 & 0.895 & 0.632 \\
\hline & AR3 & 0.732 & & & \\
\hline & AR4 & 0.806 & & & \\
\hline & AR5 & 0.809 & & & \\
\hline & AR1 & 0.810 & & & \\
\hline \multirow[t]{4}{*}{ Awareness of Consequences } & AC1 & 0.910 & 0.876 & 0.915 & 0.731 \\
\hline & AC2 & 0.903 & & & \\
\hline & AC3 & 0.823 & & & \\
\hline & AC5 & 0.776 & & & \\
\hline \multirow[t]{6}{*}{ ECSR Initiatives } & ECSR1 & 0.822 & 0.896 & 0.921 & 0.660 \\
\hline & ECSR2 & 0.840 & & & \\
\hline & ECSR3 & 0.822 & & & \\
\hline & ECSR4 & 0.835 & & & \\
\hline & ECSR5 & 0.831 & & & \\
\hline & ECSR6 & 0.717 & & & \\
\hline \multirow[t]{5}{*}{ Efficacy } & EF1 & 0.808 & 0.886 & 0.916 & 0.686 \\
\hline & EF2 & 0.823 & & & \\
\hline & EF3 & 0.864 & & & \\
\hline & EF4 & 0.835 & & & \\
\hline & EF5 & 0.810 & & & \\
\hline \multirow[t]{5}{*}{ Social Norm } & SN1 & 0.868 & 0.916 & 0.938 & 0.751 \\
\hline & SN2 & 0.908 & & & \\
\hline & SN3 & 0.910 & & & \\
\hline & SN4 & 0.851 & & & \\
\hline & SN5 & 0.791 & & & \\
\hline \multirow[t]{5}{*}{ Personal Norm } & PN1 & 0.782 & 0.866 & 0.903 & 0.652 \\
\hline & PN2 & 0.846 & & & \\
\hline & PN3 & 0.821 & & & \\
\hline & PN4 & 0.748 & & & \\
\hline & PN5 & 0.835 & & & \\
\hline \multirow[t]{5}{*}{ Purchase Intention } & PI1 & 0.825 & 0.871 & 0.907 & 0.662 \\
\hline & PI2 & 0.855 & & & \\
\hline & PI3 & 0.859 & & & \\
\hline & PI4 & 0.813 & & & \\
\hline & PI5 & 0.704 & & & \\
\hline
\end{tabular}

(strongly disagree) to 5 (strongly agree).

Social Norm: The scale to measure SN was adapted from Paul et al. (2016), which consists of six items. The response format is in a 5-point Likert's Scale ranging from strongly disagree (1) to strongly agree (5).

Personal Norm: PN was measured using a 5-item scale adapted from past studies (Han, 2014; Van der Werf and Steg, 2015). The response options ranged from 1 (strongly disagree) to 5 (strongly agree).

ECSR Initiatives: A modified scale that consists of 6 items by Turker (2008) was used to measure ECSR initiatives. Respondents completed the measure using a seven-point Likert's Scale (1strongly disagree, 7-strongly agree).

Purchase intention: PI was measured using Paul et al.'s (2016) scale, made up of 5 items measured in a 5-point Likert's Scale ranging from 1-strongly disagree to 5-strongly agree.

The full scales are available in Appendix A.

\section{Data analysis}

Developed by Ringle et al. (2015), SmartPLS 3 was used to perform the partial least squares structural equation modelling (PLS-SEM) instead of co-variance-based structural equation modelling (CB-SEM) in the current study. PLS-SEM has several advantages, including its suitability in explorative research and targets' prediction, and its flexibility in handling non-normal data and small sample sizes. Thus, SmartPLS 3 was used in this study to test the proposed hypotheses. Following a two-step analytical procedure approach, measurement and structural models were assessed (Anderson and Gerbing, 1988).

\subsection{Measurement model}

Internal consistency reliability was assessed by evaluating the Cronbach's alpha (CA) and composite reliability (CR). Constructs with high internal consistency usually have highly correlated indicators. In Table 1, the CA and CR values for all constructs were above the suggested value of 0.7 , indicating internal consistency. According to Hair et al. (2017), to achieve convergent validity, the general rules of thumb are outer loadings should be greater than 0.708 , and the average variance extracted (AVE) value should be higher than 0.5. As seen in Table 2, outer loadings for all items exceeded the benchmark of 0.7. The only item (AC4) which did not meet the benchmark was removed from the construct. Furthermore, the AVE values for all constructs were in the range of 0.632-0.751. Since the values for loadings and AVE met the threshold values recommended by Hair et al. (2017), it can be concluded that all constructs showed sufficient evidence of convergent validity.

Discriminant validity was evaluated by means of the FornellLarcker criterion and Heterotrait-Monotrait ratio of correlations (HTMT) criterion. The Fornell-Larcker criterion entails that the square root of the AVE for every construct should be higher than the inter-construct links (Fornell and Larcker, 1981), and the HTMT value between two constructs should be below 0.85 (Henseler et al., 2015). As shown in Table 2, this study does not concern discriminant validity.

\subsection{Structural model}

Following the assessment procedure for the structural model 
Table 2

Discriminant validity.

\begin{tabular}{|c|c|c|c|c|c|c|c|}
\hline \multicolumn{8}{|l|}{ Fornell-Larcker criterion } \\
\hline & 1 & 2 & 3 & 4 & 5 & 6 & 7 \\
\hline 1. Ascription of Responsibility & 0.795 & & & & & & \\
\hline 2. Awareness of Consequences & 0.402 & 0.855 & & & & & \\
\hline 3. ECSR Initiatives & 0.439 & 0.377 & 0.812 & & & & \\
\hline 4. Efficacy & 0.598 & 0.427 & 0.584 & 0.829 & & & \\
\hline 5. Personal Norm & 0.617 & 0.315 & 0.625 & 0.638 & 0.807 & & \\
\hline 6. Purchase Intention & 0.471 & 0.386 & 0.634 & 0.587 & 0.589 & 0.813 & \\
\hline 7. Social Norm & 0.513 & 0.217 & 0.367 & 0.581 & 0.582 & 0.439 & 0.867 \\
\hline \multicolumn{8}{|c|}{$\begin{array}{l}\text { Note: Values (bold) on the diagonal represent the square root of the AVE while the off-diagonals are correlations. } \\
\text { HTMT Criterion }\end{array}$} \\
\hline & 1 & 2 & 3 & 4 & 5 & 6 & 7 \\
\hline \multicolumn{8}{|l|}{ 1. Ascription of Responsibility } \\
\hline 2. Awareness of Consequences & 0.468 & & & & & & \\
\hline 3. ECSR Initiatives & 0.501 & 0.425 & & & & & \\
\hline 4. Efficacy & 0.681 & 0.486 & 0.653 & & & & \\
\hline 5. Personal Norm & 0.715 & 0.364 & 0.705 & 0.722 & & & \\
\hline 6. Purchase Intention & 0.545 & 0.436 & 0.707 & 0.659 & 0.675 & & \\
\hline 7. Social Norm & 0.580 & 0.243 & 0.397 & 0.638 & 0.652 & 0.492 & \\
\hline
\end{tabular}

suggested by Hair et al. (2017), the issue of multicollinearity was evaluated. All the variance inflation factor (VIF) values for the two endogenous variables (PN and PI) were lower than the recommended value of 5 , showing no sign of collinearity issue. Next, the model fit was assessed by evaluating the standardised root mean square residual (SRMR) (Henseler et al., 2016). As the SRMR value for this research model was 0.057 , lower than the threshold value of 0.08 , it can be concluded that the model is a reasonable model fit.

To assess the significance of coefficient for every path proposed in the research model, a bootstrapping technique was performed with 5000 re-samples (Hair et al., 2017). The outcomes in Table 3 displayed that AC has a substantial positive effect on PI, but no significant effect on PN. Hence, H1b is supported but H1a is not supported. It was also found that AR has a substantial influence on $\mathrm{PN}$, but no significant influence on PI. Thus, H2a is supported, while $\mathrm{H} 2 \mathrm{~b}$ is not supported. Additionally, efficacy, SN, and ECSR initiatives were found to have substantial positive impact on PI and PN, supporting H3a, H3b, H4a, H4b, H5a, and H5b. Lastly, PN was found to have a significant positive effect on PI, which supports H6. The effect size for each relationship is reported in Table 3 and the interpretation of the $\mathrm{f}^{2}$ is as follows: 0.02 (small), 0.15 (medium), and 0.35 (large).

To test the significance of the indirect effect (mediation effect), the bootstrapping method was applied (Preacher and Hayes, 2008). Based on Table 3, the results demonstrated that the mediation effect of PN has a significant impact on the relationships between PI and AR (beta $=0.044$, t-value $=2.297$, p-value $=0.022$ ), efficacy (beta $=0.026$, t-value $=2.026$, p-value $=0.043)$, SN $($ beta $=0.039$, t-value $=2.462$, p-value $=0.014)$, and ECSR initiatives (beta $=0.056, \mathrm{t}$-value $=2.810, \mathrm{p}$-value $=0.005$ ), since all confidence intervals do not contain zero, supporting H7b, H7c, H7d, and H7e. However, PN did not significantly mediate the relationship between $\mathrm{AC}$ (beta $=-0.007$, $\mathrm{t}$-value $=1.097$, $\mathrm{p}$-value $=0.273$ ) and PI. Hence, $\mathrm{H} 7 \mathrm{a}$ is not supported.

In addition to assessing the significance of path coefficients, the model's predictive power was also assessed by looking at the coefficient of determination $\left(\mathrm{R}^{2}\right)$ values of the endogenous constructs (Hair et al., 2017). The model was able to explain $60.1 \%$ of the variance in PN and $50.1 \%$ of the variance in PI. In addition, a blindfolding procedure was conducted with an omission distance of 7 to obtain the Stone-Geisser's $Q^{2}$ value (Hair et al., 2017). The results showed that the $\mathrm{Q}^{2}$ value for $\mathrm{PN}$ and $\mathrm{PI}$ is 0.330 and 0.390 , respectively. Since both values are above zero, the research model was considered to have predictive relevance. Apart from that, a PLSpredict analysis (Shmueli et al., 2016) was also performed. Table 4 shows that the $\mathrm{Q}^{2}$ predict is greater than 0 for PN and PI,

Table 3

Structural model.

\begin{tabular}{|c|c|c|c|c|c|c|c|c|}
\hline & Direct effect & Beta & $\mathrm{BCCI}(5 \%-95 \%)$ & Standard error & t-value & p value & Decision & $\mathrm{f}^{2}$ \\
\hline H1a & $\mathrm{AC}->\mathrm{PN}$ & -0.041 & {$[-0.091,0.013]$} & 0.032 & 1.268 & 0.102 & Not Supported & 0.003 \\
\hline H1b & $A C->$ PI & 0.099 & {$[0.031,0.160]$} & 0.039 & 2.516 & 0.006 & Supported & 0.015 \\
\hline $\mathrm{H} 2 \mathrm{a}$ & $\mathrm{AR}->\mathrm{PN}$ & 0.267 & {$[0.182,0.350]$} & 0.052 & 5.092 & 0.000 & Supported & 0.102 \\
\hline $\mathrm{H} 2 \mathrm{~b}$ & $\mathrm{AR}->\mathrm{PI}$ & 0.035 & {$[-0.052,0.117]$} & 0.051 & 0.681 & 0.248 & Not Supported & 0.001 \\
\hline Н3а & $\mathrm{EF}->\mathrm{PN}$ & 0.158 & {$[0.071,0.246]$} & 0.053 & 2.954 & 0.002 & Supported & 0.027 \\
\hline H3b & $\mathrm{EF}->\mathrm{PI}$ & 0.169 & {$[0.071,0.263]$} & 0.058 & 2.927 & 0.002 & Supported & 0.024 \\
\hline $\mathrm{H} 4 \mathrm{a}$ & $\mathrm{SN}->\mathrm{PN}$ & 0.236 & {$[0.162,0.318]$} & 0.046 & 5.098 & 0.000 & Supported & 0.087 \\
\hline $\mathrm{H} 4 \mathrm{~b}$ & $\mathrm{SN}->\mathrm{PI}$ & 0.077 & {$[0.008,0.144]$} & 0.041 & 1.886 & 0.030 & Supported & 0.007 \\
\hline $\mathrm{H} 5 \mathrm{a}$ & ECSR - > PN & 0.344 & {$[0.071,0.246]$} & 0.051 & 6.814 & 0.000 & Supported & 0.190 \\
\hline $\mathrm{H} 5 \mathrm{~b}$ & ECSR - > PI & 0.352 & {$[0.272,0.433]$} & 0.048 & 7.303 & 0.000 & Supported & 0.134 \\
\hline H6 & $\mathrm{PN}->\mathrm{PI}$ & 0.164 & {$[0.072,0.256]$} & 0.056 & 2.908 & 0.002 & Supported & 0.021 \\
\hline \multicolumn{9}{|c|}{ One-tailed test } \\
\hline & Indirect Effect & Beta & BCCI $(2.50 \%-97.5 \%)$ & Standard error & t- value & p-value & Decision & \\
\hline $\mathrm{H} 7 \mathrm{a}$ & $\mathrm{AC}->\mathrm{PN}->\mathrm{PI}$ & -0.007 & {$[-0.021,0.004]$} & 0.006 & 1.097 & 0.273 & Not Supported & \\
\hline $\mathrm{H} 7 \mathrm{~b}$ & $\mathrm{AR}->\mathrm{PN}->\mathrm{PI}$ & 0.044 & {$[0.011,0.086]$} & 0.019 & 2.297 & 0.022 & Supported & \\
\hline $\mathrm{H} 7 \mathrm{c}$ & $\mathrm{EF}->\mathrm{PN}->\mathrm{PI}$ & 0.026 & {$[0.005,0.054]$} & 0.013 & 2.026 & 0.043 & Supported & \\
\hline $\mathrm{H} 7 \mathrm{~d}$ & $\mathrm{SN}->\mathrm{PN}->\mathrm{PI}$ & 0.039 & {$[0.011,0.073]$} & 0.016 & 2.462 & 0.014 & Supported & \\
\hline $\mathrm{H} 7 \mathrm{e}$ & ECSR - > PN - > PI & 0.056 & {$[0.017,0.097]$} & 0.020 & 2.810 & 0.005 & Supported & \\
\hline
\end{tabular}


suggesting that the prediction error of the PLS-SEM results is smaller than the prediction error of mean values. Furthermore, compared to the naïve linear regression model (LM), the PLS benchmark yields lower prediction errors in terms of RMSE (or MAE) for most indicators, indicating the model has medium predictive power.

\section{Discussion}

First, the significant positive effect of AC on PI as discovered in this research specifies that consumers, who are mindful of the negative influences that non-green beauty products have on the environment, are more probable in buying green beauty products. This result is in line with the results from previous studies (Vaske et al. 2015; Zhang et al., 2014; Ergen et al. 2014). In previous researches, AC improved green behavioural intention. Contextually, the more an individual is shown to the knowledge about the seriousness of non-green beauty products on the environment, the higher the purpose to buy green beauty products among the nongreen consumers. With the positive outcome between AC and purpose, similar outcome was anticipated with the connection between AC and PN. Knowing that non-green beauty products are bad for the environment, may affect one's intrinsic emotion.

However, surprisingly, AC was found to have no significant influence on PN, suggesting that PN is not shaped by how consumers view the consequences of buying non-green beauty products. Nevertheless, the result is in line with a study by Lauper et al. (2015) on street-traffic noise prevention that was based on the NAT, showing that AC was not a significant predictor of PN. The result suggests that being mindful of consequences alone is inadequate to trigger intrinsic feeling of moral obligation.

This study also found no relationship between AR and the PI of green beauty products. This means the feeling of responsibility alone does not equate action among consumers. Nevertheless, the influence of AR on PI through PN is significant. This finding is supported by De Groot and Steg (2009), who studied five different situations of pro-social behaviour. They found that those who feel responsible for a challenging situation will feel a sense of guilt, which will then influence their action indirectly.

The third activator examined in this study is efficacy. Efficacy has been shown to have a significant influence on both PN and the PI of green beauty products. The result is consistent with a previous study by Wan et al. (2014), which found that efficacy is the most important variable in behavioural intention. Efforts by cosmetics companies to produce more green products have increased their availability and accessibility. Studies by Harland et al. (2007), and Steg and De Groot (2010) found that efficacy has a positive relationship with PN, which conforms with results in the current study. The increased ability to improve accessibility to green beauty products has increased consumers' ethical obligation to perform environmentally responsible action.

The next point of discussion is the integration of SN into the NAT model. As investigated, the current study found that SN significantly influences both PN and PI. This result is consistent with those of previous studies by Onwezen et al. (2014) and Han (2014), on the positive effect of SN on PN, whereas the significant effect of SN on behavioural purpose conforms with the results of studies by Rezai et al. (2013) and Garcia-Valinas et al. (2012). Thus, it can be surmised that social pressures experienced by consumers can result in their feeling obligated to perform an action, which ultimately affects their PI.

Finally, ECSR initiatives by corporations were integrated into the NAT model to examine their impact on PN and PI. The results show that not only did ECSR initiatives have a significant influence on both PN and PI, but also had the strongest direct relationship with PN and the PI of green beauty products.

In this study, the effectiveness of PN as a mediator variable was also assessed and it was found that PN mediates four out of five activators, which are AR, efficacy, SN, and ECSR initiatives, to the PI of green beauty products. Based on the result, AC did not have an indirect relationship with the PI of green beauty products via PN. According to van der Werff et al. (2015), the relationship between $\mathrm{AC}$ and $\mathrm{PN}$ is mediated by AR, which then leads to behavioural change. This relationship is supported by the result in this study, that there is no significant direct relationship between AC and PN. PN cannot be activated by AC. De Groot and Steg (2009) explained that in order to activate PN, an individual must first feel the AC and AR. PN is then activated, leading to pro-environmental behaviour. The added variables, such as SN and ECSR initiatives, were successfully mediated by PN. These results have bridged the gap of knowledge pertaining to the effectiveness of PN as a mediator variable.

This study is limited to the investigation on the non-green consumers of green beauty products. The comparison between non-green consumers and the consumers of green beauty products can be explored in future research. Furthermore, the use of crosssectional data in this study might reduce the power to draw casual inferences. Hence, it would better to collect longitudinal data in future studies. Lastly, this study focused on investigating nongreen consumers' purchase intention of green beauty products

Table 4

PLS predict assessment.

\begin{tabular}{|c|c|c|c|c|c|c|c|c|c|}
\hline \multicolumn{10}{|c|}{ Construct Prediction Summary } \\
\hline & $\mathrm{Q}^{2}$ & & & & & & & & \\
\hline Personal norm & 0.556 & & & & & & & & \\
\hline Purchase Intention & 0.422 & & & & & & & & \\
\hline \multicolumn{10}{|c|}{ Indicator Prediction Summary } \\
\hline & PLS & & & LM & & & PLS-LM & & \\
\hline & RMSE & MAE & $\mathrm{Q}^{2}$ predict & RMSE & MAE & $\mathrm{Q}^{2}$ predict & RMSE & MAE & $\mathrm{Q}^{2}$ predict \\
\hline PN4 & 0.765 & 0.571 & 0.312 & 0.768 & 0.569 & 0.307 & -0.003 & 0.002 & 0.005 \\
\hline PN2 & 0.664 & 0.495 & 0.390 & 0.664 & 0.497 & 0.390 & 0.000 & -0.002 & 0.000 \\
\hline PN5 & 0.665 & 0.502 & 0.434 & 0.679 & 0.516 & 0.409 & -0.014 & -0.014 & 0.025 \\
\hline PN3 & 0.664 & 0.511 & 0.432 & 0.669 & 0.500 & 0.423 & -0.005 & 0.011 & 0.009 \\
\hline PN1 & 0.728 & 0.539 & 0.351 & 0.736 & 0.545 & 0.337 & -0.008 & -0.006 & 0.014 \\
\hline PI5 & 0.831 & 0.644 & 0.193 & 0.841 & 0.653 & 0.174 & -0.010 & -0.009 & 0.019 \\
\hline PI4 & 0.657 & 0.504 & 0.303 & 0.680 & 0.515 & 0.252 & -0.023 & -0.011 & 0.051 \\
\hline PI1 & 0.632 & 0.473 & 0.381 & 0.640 & 0.473 & 0.365 & -0.008 & 0.000 & 0.016 \\
\hline PI2 & 0.620 & 0.491 & 0.370 & 0.626 & 0.489 & 0.359 & -0.006 & 0.002 & 0.011 \\
\hline PI3 & 0.649 & 0.501 & 0.332 & 0.664 & 0.517 & 0.301 & -0.015 & -0.016 & 0.031 \\
\hline
\end{tabular}


using the NAT only. Future studies may consider using other theories such as ethics theory, the theory of planned behaviour, neutralization theory and others.

\subsection{Managerial implications}

Given that AC is a significant predictor of PI, cosmetics companies' advertising content should place more focus on the impact of buying non-green beauty products on the environment (Rahbar and Wahid, 2011). Once consumers are exposed to this information, they might be more willing to buy environmentally friendly beauty products (Lai and Cheng, 2015). The results of this study have shown that efficacy, AC, and SN, are all significant predictors of PI. SN has shown to be one of the significant predictors of PI, which means that the non-green consumers of green beauty products value the opinion of others close to them. Therefore, cosmetics companies could include advertising messages that emphasise green behaviour as a norm in the current society. Given that ECSR initiatives are the strongest predictors of PI, cosmetics companies should also enhance their efforts in promoting ECSR initiatives because these initiatives are viewed by consumers as important criteria in buying green beauty products. Thus, it is advisable to communicate corporate ECSR initiatives with consumers to improve consumers' awareness of companies' current efforts towards improving the environment.

\subsection{Theoretical implications}

This research has some theoretical contributions to academic literature. First, it verified that a protracted NAT model is beneficial in forecasting consumers' PI towards green beauty products, as the empirical data confirmed that the model has a high predictive power of $R^{2}, Q^{2}$, and $Q^{2}$ predict value. Second, the study extended the original NAT framework by including two additional variables, namely SN and ESCR initiatives, to predict PN and PI. These two added variables were found to be significant predictors of PN and PI. Third, the study investigated the mediation effect of PN. The findings show that AR, efficacy, SN, and ECSR initiatives have a significant direct positive influence on PI, and that PN is a significant mediator. The findings suggest that these factors not only directly influence consumers' PI, but also activate consumers' moral obligation. As a result, consumers may be influenced to make greener consumption choices, ultimately affecting their PI.

\section{Conclusion}

Overall, this study has shown that the research model is useful and comprehensive to explain non-green consumers' PI of green beauty products. Particularly, it was found that those who have a strong awareness about the repercussions of using non-green beauty products, also have a stronger purpose to buy green beauty products in the future. Besides that, efficacy, alongside SN and ECSR initiatives enhances the purpose to buy green beauty products among the non-green consumers. This study has also found that stronger moral obligation or PN leads to stronger PI. PN can be affected by AR, efficacy, SN, and ECSR initiatives. The effectiveness of PN as a mediator has been tested and shown to be a strong mediator even on new added variables, such as SN and ECSR initiatives. From the results, it can be concluded that having a holistic marketing campaign of green beauty products, which includes negative impacts of non-green beauty products on the environment as a central message, as well as purchasing green beauty products as an acceptable norm, may be able to positively influence the non-green consumers to start using green beauty products. Making green beauty products available and accessible in the market is also an important criterion in planning a successful marketing campaign. As per result of this study, efficacy, and SN both have positive impact on one's moral obligation and purpose. Finally, the results also suggest the importance of ECSR initiatives to be included in planning a successful marketing campaign, especially to convert non-green consumers to become consumers of green beauty products.

\section{CRediT authorship contribution statement}

Siti Munerah: Conceptualization, Writing - original draft, preparation, Investigation, Methodology, Writing - review \& editing. Kian Yeik Koay: Validation, Formal analysis, Data curation, Writing - review \& editing. Seethaletchumy Thambiah: Writing review \& editing.

\section{Declaration of competing interest}

The authors declare that they have no known competing financial interests or personal relationships that could have appeared to influence the work reported in this paper.

\section{Appendix A. Supplementary data}

Supplementary data to this article can be found online at https://doi.org/10.1016/j.jclepro.2020.124192.

Appendix B. Scales

\section{AWARENESS OF CONSEQUENCES}

1. Non-environmentally friendly cosmetic products can cause environmental pollution due to its non-recyclable packaging and unnatural ingredients.

2. Non-environmentally friendly cosmetic products contribute to ecological damage.

3. Cosmetic industry causes environmental deterioration (i.e. chemical waste, transportation, cosmetic packaging, etc.).

4. I don't care about the carbon emissions cause by the cosmetic industry.

5. An environmentally responsible cosmetic company practicing water/energy conservation, water reduction, and diverse green activities helps to minimise environmental degradation.

\section{ASCRIPTION OF RESPONSIBILITY}

1. I feel jointly responsible for the usage of non-environmentally friendly cosmetic products to environmental deterioration.

2. I believe that every cosmetic user is partly responsible for the pollution caused by the cosmetic manufacturers.

3. Every cosmetic user must take responsibility of the environmental problems caused by the cosmetic industry.

4. I feel upset by the amount of product packaging my household throws away.

5. I am concerned about my purchase behaviour and the environment.

\section{EFFICACY}

1. I think the purchase of environmentally friendly cosmetic products contribute to a clean environment.

2. I think the purchase of environmentally friendly cosmetic products will reduce environmental deterioration. 
3. I think I can help to reducing environmental problems by being eco-friendly.

4. By purchasing environmentally friendly cosmetic products, I can encourage others to do the same.

5. I personally can change my purchase pattern towards environmentally friendly cosmetic products.

\section{SOCIAL NORM}

1. I have the support from my friends and peers to purchase environmentally friendly cosmetic products.

2. My family members suggested that I should purchase environmentally friendly cosmetic products.

3. Family members would prefer me to try environmentally friendly cosmetic products.

4. My friends' positive opinion influences me to purchase environmentally friendly cosmetic product.

5. I care about what others think of me, so I will try to use environmentally friendly product.

\section{PERSONAL NORM}

1. I would feel guilty if I do not reduce environmental deterioration.

2. I feel it is important that cosmetic users in general make an ecofriendly decision when purchasing a cosmetic product.

3. I feel an obligation to purchase environmentally friendly cosmetic products rather than the non-environmentally friendly ones.

4. I feel it is harmful to use non-environmentally friendly cosmetic products.

5. My own value inspires me to purchase environmentally friendly cosmetic products.

\section{ECSR INITIATIVES}

1. I prefer to buy from companies that provide accurate information about its products to its customer.

2. I prefer companies that provide full details about its ingredients to its customer.

3. By buying from product with eco-label, I indirectly influence environmental protection.

4. I support companies that contribute to campaigns and projects that promote the well being of the society.

5. I would like to use the products from companies that participate in activities that aim to protect and improve the quality of the natural environment.

6. I prefer to buy from companies that make sufficient monetary contribution to NGOs that promotes environmental preservation.

\section{PURCHASE INTENTION}

1. I am willing to use environmental-friendly cosmetic products in the future.

2. I definitely want to purchase environmentally friendly cosmetic products very soon.

3. I will take initiatives to find environmentally friendly cosmetic products in the future.

4. I will consider switching to environmentally friendly cosmetic products for ecological reasons.
5. I will consume environmentally friendly cosmetic products even if they are more expensive than non-environmentally friendly ones.

\section{References}

Anderson, J.C., Gerbing, D.W., 1988. Structural equation modeling in practice: a review and recommended two-step approach. Psychol. Bull. 103 (3), 411-423. Annuar, M.M., Mohamad, O., 2012. Consumer response to cause-related marketing: a case of Malaysia. J. Asian Bus. Strat. 2 (4), 71-76.

Antil, J., 1984. Socially responsible consumers: profile and implications for public policy. J. Macroecon. 4 (2), 18-39.

Bamberg, S., Moser, G., 2007. Twenty years after Hines, Hungerford and Tomera: a new meta-analysis of psycho-social determinants of pro-environmental behaviour. J. Environ. Psychol. 27 (1), 14-25.

Belk, R., Devinney, T., Eckhardt, G., 2005. Consumer ethics across cultures. Consum. Mark. Cult. 8 (3), 275-289.

Bhattacharya, C., Sen, S., 2004. Doing better at doing good: when, why, and how consumers respond to corporate social initiatives. Calif. Manag. Rev. 47 (1), $9-24$.

Biel, A., Thøgersen, J., 2007. Activation of social norms in social dilemmas: a review of the evidence and reflections on the implications for environmental behaviour. J. Econ. Psychol. 28 (1), 93-112.

Caruana, R., Chatzidakis, A., 2014. Consumer social responsibility $\left(C_{N} C R\right)$ : toward a multi-level, multi-agent conceptualization of the "Other CSR". J. Bus. Ethics 121, 577-592.

Chekima, B., Wafa, S.A., Igau, O.A., Chekima, S., Sondoh, S.L., 2015. Examining green consumerism motivational drivers: does premium price and demographics matter to green purchasing? J. Clean. Prod. 1-15.

Chen, Y., Chang, C., 2012. Enhance green purchase intentions: the roles of green perceived value, green perceived risk, and green trust. Manag. Decis. 50 (3), $502-520$.

Chen, M., Lee, C., 2015. The impacts of green claims on coffee consumers' purchase intention. Br. Food J. 117 (1), 195-209.

De Groot, J., Steg, L., 2009. Morality and prosocial behavior: the role of awareness, responsibility, and norms in the norm activation model. J. Soc. Psychol. 149 (4), 425-449.

Devinney, T.M., Auger, P., Eckhart, G.M., 2010. The Myth of the Ethical Consumer. Cambridge University Press, NY.

Doran, R., Daniel, H., Larsen, S., 2015. Attitudes, efficacy beliefs and willingness to pay for environmental protection when travelling. Tourism Hospit. Res. 15 (4), 281-292.

Ebreo, A., Vining, J., Cristancho, S., 2003. Responsibility for environmental problems and the consequences of waste reduction: a test of the norm-activation model. J. Environ. Syst. 29 (3), 219-244.

Ergen, A., Bozkurt, F., Giray, C., 2014. Activism: a strong predictor of proactive environmentally friendly buying behavior in Turkey. Int. J. Res. Bus. Soc. Sci. 3 (1), 2147-4478.

Feldman, P., Vasquez-Parraga, A., 2013. Consumer social responses to CSR initiatives versus corporate abilities. J. Consum. Market. 30 (2), 100-111.

Folse, A.G., Niedrich, R.W., Grau, S.L., 2010. Cause-related marketing: the effects of purchase quantity and firm donation amount on consumer inferences and participation intentions. J. Retailing 86 (4), 295-309.

Garcia-Valinas, M.A., Macintyre, A., Torgler, B., 2012. Volunteering, proenvironmental attitudes and norms. J. Soc. Econ. 41 (4), 455-461.

Gifford, R., 2011. The dragon of inaction: psychological barriers that limit climate change mitigation and adaptation. Am. Psychol. 66 (4), 290-302.

Gilg, A., Barr, S., Ford, N., 2005. Green consumption or sustainable lifestyles? Identifying the sustainable consumer. Futures 37, 481-504.

Grimmer, M., Bingham, T., 2013. Company environmental performance and consumer purchase intentions. J. Bus. Res. 66 (10), 1945-1953.

Hair, J.F.J., Hult, G.T.M., Ringle, C.M., Sarstedt, M., 2017. A Primer on Partial Least Squares Structural Equation Modeling (PLS-SEM), second ed. Sage Pub, Thousand Oaks CA.

Han, H., 2014. The norm activation model and theory-broadening: individuals' decision-making on environmentally-responsible convention attendance. J. Environ. Psychol. 40, 462-471.

Han, H., Hwang, J., Kim, J., Jung, H., 2015. Guests' pro-environmental decisionmaking process: broadening the norm activation framework in a lodging context. Int. J. Hospit. Manag. 47, 96-107.

Harland, P., Staats, H., Wilke, H., 2007. Situational and personality factors as direct or personal norm mediated predictors of pro-environmental behavior: questions derived from norm-activation theory. Basic Appl. Soc. Psychol. 29 (4), 323-334.

Henseler, J., Ringle, C.M., Sarstedt, M., 2015. A new criterion for assessing discriminant validity in variance-based structural equation modelling. J. Acad. Market. Sci. 43 (1), 115-135.

Henseler, J., Hubona, G., Ray, P.A., 2016. Using PLS path modeling in new technology research: updated guidelines. Ind. Manag. Data Syst. 116 (1), 2-20.

Hofenk, D., Birgelen, M.V., Bloemer, J., Semejin, J., 2010. Integrating the theory of planned behaviour and the norm-activation theory to explain proenvironmental buying behaviour. Ins. Manag. Res.

Hsu, C.L., Chang, C.Y., Yansritakul, C., 2017. Exploring purchase intention of green 
skincare products using the theory of planned behaviour: testing the moderating effects of country of origin and price sensitivity. J. Retailing Consum. Serv. 34, 145-152.

Jardak, K., Drogui, P., Daghrir, R., 2016. Surfactants in aquatic and terrestrial environment: occurrence, behaviour, and treatment processes. Environ. Sci. Pollut. Res. 23, 3195-3216.

Jimenez, M., Yang, K., 2008. How guilt level affects green advertising effectiveness? J. Creativ. Commun. 3 (3), 231-254.

Juliano, C., Magrini, G., 2017. Cosmetic ingredients and emerging pollutants of environmental and health concern. A mini-review. Cosmetics 4 (2), 11. https:// doi.org/10.3390/cosmetics4020011.

Joanes, T., 2019. Sufficiency for sustainability: determinants and strategies for reducing clothing consumption. Copenhagen Bus. School.

Kaiser, F.G., Shimoda, T., 1999. Responsibility as a predictor of ecological behaviour. J. Environ. Psychol. 19 (3), 243-253.

Kaiser, F.G., Hubner, G., Bogner, F.X., 2005. Contrasting the theory of planned behavior with the value-belief-norm model in explaining conservation behaviour. J. Appl. Soc. Psychol. 35 (10), 2150-2170.

Kaur, S., 2014. Impact of green marketing on consumer's behaviour. Commun. Manag. 3 (5).

Khojastehpour, M., Johns, R., 2014. The effect of environmental CSR issues on corporate/brand reputation and corporate profitability. Eur. Bus. Rev. 26 (4), 330-339.

Kim, H.Y., Chung, J.E., 2011. Consumer purchase intention for organic personal care products. J. Consum. Market. 28 (1), 40-47.

Kong, W., Harun, A., Rini, S.S., Lily, J., 2014. The influence of consumers' perception of green products on green purchase intention. Int. J. Asian Soc. Sci. 4 (8), 924-939.

Lai, C.K.M., Cheng, E.W.L., 2015. Green purchase behavior of undergraduate students in Hong Kong. Soc. Sci. J. 53 (1), 67-76.

Lalit, M.J., Sahasakmontri, K., 1998. Green marketing of cosmetics and toiletries in Thailand. J. Consum. Market. 15 (3), 78-88.

Lauper, E., Moser, S., Fischer, M., Matthies, E., 2015. Explaining car drivers' intention to prevent road-traffic noise: an application of the norm activation model. Environ. Behav. 1-28.

Ling, C.Y., 2013. Consumers' purchase intention of green products: an investigation of the drivers and moderating variable. Elixir Marketing Manag 57A, 14503-14509.

Lopez, R., 2014. 'No' to microbeads in cosmetics. http://www.thestar.com.my/News/ Environment/2014/02/17/No-to-microbeads-in-cosmetics/. (Accessed 23 June 2014).

Manning, L., 2013. Corporate and consumer social responsibility in the food supply chain. Br. Food J. 115 (1), 9-29.

Matthies, E., Selge, S., Klöckner, C., 2012. The role of parental behavior for the development of behaviour specific environmental norms: the example of recycling and re-use behaviour. J. Environ. Psychol. 32, 277-284.

Milfont, T., Sibley, C., Duckitt, J., 2010. Testing the moderating role of Norm Activation on the relationship between values and environmental behaviour. J. Cross Cult. Psychol. 41 (1), 124-131.

Moser, A.K., 2015. Thinking green, buying green? Drivers of pro-environmental purchasing behaviour. J. Consum. Market. 32 (2), 167-175.

Murphy, R., Graber, M., Stewart, A., 2010. Green marketing: a study of the impact of green marketing on consumer behavior during recession. Bus. Rev. Cambridge. 16 (1), 134-140.

Nik Ramli, N., 2009. Awareness of eco-label in Malaysia's green marketing initiative. Int. J. Bus. Manag. 4 (8), 132-141.

Nik Ramli, N., Rahman, N., Khalid, S., 2014. Environmental corporate social responsibility (ECSR) as a strategic marketing initiatives. Procedia - Social and Behav. Sci. 130, 499-508.

Noaa Research News, 2018. Study: pollution from personal care products comparable to tailpipe emissions in Boulder. https://research.noaa.gov/News/ArtMID/ 451/ArticleID/2349/Study-Pollution-from-personal-care-products-comparableto-tailpipe-emissions-in-Boulder/. (Accessed 23 September 2019).

Nor Irwani, A.R., Nik Ramli, N.A.R., Shaiful, A.K., 2014. Environmental corporate social responsibility (ECSR): exploring its influence on corporate image. J. Manag. Sci. 1 (2), 21-38.

OECD, 2009. Sustainable manufacturing and eco-innovation: towards a green economy. Policy Brief. https://www.oecd.org/env/consumption-innovation/ 42957785.pdf/. (Accessed 22 March 2017).

Onwezen, M., Bartels, J., Antonides, G., 2014. Environmentally friendly consumer choices: cultural differences in the self-regulatory function of anticipated pride and guilt. J. Environ. Psychol. 40, 239-248.

Park, J., Ha, S., 2012. Understanding pro-environmental behaviour: a comparison of sustainable consumers and apathetic consumers. Int. J. Retail Distrib. Manag. 40 (5), 388-403.

Payne, K., 2013. The effects of self-efficacy on pro-environmental intentions. The Plymouth Student Scientist 6 (1), 224-238.

Preacher, K.J., Hayes, A.F., 2008. Asymptotic and resampling strategies for assessing and comparing indirect effects in multiple mediator models. Behav. Res. Methods 40 (3), 879-891.

Pudaruth, S., Devi, T., Yogini, J., Seewoo, D., 2015. Gender-based differences in understanding the purchasing patterns of eco-friendly cosmetics and beauty care products in Mauritius: a study of female customers. Soc. Responsib. J. 11 (1), $179-198$.
Quazi, A., Amran, A., Nejati, M., 2016. Conceptualizing and measuring consumer social responsibility: a neglected aspect of consumer research. Int. J. Consum. Stud. 40, 48-56.

Rahbar, E., Wahid, N.A., 2011. Investigation of green marketing tools' effect on consumers' purchase behaviour. Bus. Strat. 12 (2), 73-83.

Rezai, G., Phuah, K., Mohammed, Z., Shamsudin, M., 2013. Going green: survey of perceptions and intentions among Malaysian consumers. Int. Bus. Manag. 6 (1), 104-112.

Ringle, C.M., Wende, S., Becker, J.M., 2015. SmartPLS 3. www.smartpls.com. (Accessed 20 January 2017).

Schlaile, M.P., Klein, K., Bock, W., 2018. From bounded morality to consumer social responsibility: a transdisciplinary approach to socially responsible consumption and its obstacles. J. Bus. Ethics 149, 561-588.

Schultz, P.W., Gouveia, V., Cameron, L.D., Tankha, G., Schmuck, P., Franek, M., 2005. Values and their relationship to environmental concern and conservation behaviour. J. Cross Cult. Psychol. 36 (4), 457-475.

Schwartz, S.H., 1970. Elicitation of moral obligation and self-sacrificing behavior: an experimental study of volunteering to be a bone marrow donor. J. Pers. Soc. Psychol. 15 (4), 283-293.

Schwartz, S.H., 1977. Normative influence on altruism. Adv. Exp. Soc. Psychol. 10, $222-275$

Schwartz, S.H., Howard, J.A., 1981. A normative decision-making model of altruism in Rushton. In: P, J., Sorrentino, R.M. (Eds.), Altruism and Helping Behavior: Social, Personality, and Developmental Perspectives. Lawrence Erlbaum, Hillsdale, NJ, pp. 189-211.

Shahbandeh, M., 2019. Global value of the cosmetics market. https://www.statista. com/statistics/585522/global-value-cosmetics-market/. (Accessed 18 December 2019).

Sharma, S., Garisson, S., 2014. GCI magazine. http://www.gcimagazine.com/ markettrends/segments/natural/Make-Your-Green-Claims-Mean-Something264451601.html/. (Accessed 23 June 2014).

Shmueli, G., Ray, S., Velasquez Estrada, J.M., Chatla, S.B., 2016. The elephant in the room: evaluating the predictive performance of PLS models. J. Bus. Res. 69 (10), 4552-4564.

Song, Y., Zhao, C., Zhang, M., 2019. Does haze pollution promote the consumption of energy-saving appliances in China? An empirical study based on norm activation model. Resour. Conserv. Recycl. 145, 220-229.

Steg, L., Groot, J., 2010. Explaining prosocial intentions: testing causal relationships in the norm activation model. Br. J. Soc. Psychol. 49, 725-743.

Steinhorst, J., Klockner, C.A., Matthies, E., 2015. Saving electricity - for the money or the environment? Risk of limiting pro-environmental spillover when using monetary framing. J. Environ. Psychol. 43, 125-135.

Stern, P., 2000. Toward a coherent theory of environmentally significant behaviour. J. Soc. Issues 56 (3), 407-424.

Tan, B., Lau, T., 2010. Attitude towards the environment and green products: consumers' perspective. Manag. Sci. Eng. 4 (2), 27-39.

Thøgersen, J., 2006. Norms for environmentally responsible behavior: an extended taxonomy. J. Environ. Psychol. 2 (4), 247-261.

Turaga, R.M.R., Howarth, R.B., Borsuk, M.E., 2010. Pro-environmental behavior: rational choice meets moral motivation. Ann. N. Y. Acad. Sci. 1185 (1), 211-224.

UNEP, 2015. Plastics in cosmetics. http://wedocs.unep.org/handle/20.500.11822/ 9664/. (Accessed 15 February 2016).

Van der Werff, E., Steg, L., 2015. One model to predict them all: predicting energy behaviours with the norm activation model. En. Res. Soc. Sci. 6, 8-14.

Van Marrewijk, M., 2003. Concept and definition of CSR and corporate sustainability: between agency and communion. J. Bus. Ethics 44, 95-105.

Vaske, J.J., Jacobs, M.H., Espinosa, T.K., 2015. Carbon footprint mitigation on vacation: a norm activation model. J. Out. Rec. Tour. 11, 80-86.

Vitell, S.J., 2015. A case for consumer social responsibility $\left(C_{N} C R\right)$ : including a selected review of consumer ethics/social responsibility research. J. Bus. Ethics 130, 767-774.

Wan, C., Shen, G.Q., Yu, A., 2014. The role of perceived effectiveness of policy measures in predicting recycling behaviour in Hong Kong. Resour. Conserv. Recycl. 83, 141-151.

Webster, J., 1975. Determining the characteristics of the socially conscious consumer. J. Consum. Res. 2 (3), 188-196.

White, K., Macdonnell, R., Dahl, D., 2011. It's the mind-set that matters: the role of construal level and message framing in influencing consumer efficacy and conservation behaviour. J. Market. Res. 48 (3), 472-485.

Wigley, S., 2008. Gauging consumers' responses to CSR activities: does increase awareness make cents? Publ. Relat. Rev. 34 (3), 306-308.

Young, W., Hwang, K., Oates, C., 2010. Sustainable consumption: green consumer behaviour when purchasing products. Sustain. Dev. 18 (1), 20-31.

Yusof, J.M., Singh, G.K.B., Razak, R.A., 2013. Purchase intention of environmentfriendly automobile. Procedia - Soc. Behav. Sci. 85, 400-410.

Zhang, Y., Wang, Z., Zhou, G., 2013. Antecedents of employee electricity saving behavior in organizations: an empirical study based on norm activation model. Energy Pol. 62, 1120-1127.

Zhang, Y., Zhang, H., Zhang, J., Cheng, S., 2014. Predicting residents' proenvironmental behaviors at tourist sites: the role of awareness of disaster's consequences, values, and place attachment. J. Environ. Psychol. 40, 131-146.

Zhu, B., 2013. The impact of green advertising on consumer purchase intention of green products. SSRN. J. SSRN. Elec. J. 3 (3), 72-80. 